\title{
Multisectoral collaboration for health and sustainable development
}

\author{
Learning together, from success and from failure
}

\section{W}

ith 17 goals and many more targets, the all encompassing 2030 Agenda for Sustainable Development has been criticised as being too warm and cuddly, ${ }^{1}$ and its unwieldy message can feel like little more than a call for everyone to work together. But this rallying call may, in fact, catalyse one of the greatest breakthroughs by 2030 . We believe that much of the power of the sustainable development goals (SDGs) is in the 17th goal: "partnerships for the goals." This final goal could easily be overlooked by cynics as an administrative add-on, aiming merely to scoop up financing. It is here, however, that the goals' power is hidden within broad indicators such as "policy coherence" and "multistakeholder partnerships."

SDG 17 provides a powerful incentive to discuss matters regarded as beyond the remit of the health sector-in strategies and service delivery programmes and in the pages of medical journals. We also know that a substantial proportion of the gains for maternal and child health in the millennium development goal era were associated with interventions outside of the health sector. ${ }^{2}$ And with a recent study of the health related SDG indicators showing offtarget trajectories, ${ }^{3}$ the collaborative power of goal 17 may be one route to getting us back on track.

This week, The BMJ publishes a series of articles that attempt to unpick how best to work across sectors to achieve better health and sustainable development. ${ }^{4}$ The series reflects a collaborative process, conducted for over a year, involving over 500 participants from 12 countries, including authors and contributors to multistakeholder dialogues, and analytical work to develop country case studies. Country teams led the studies, guided by a methods framework ${ }^{5}$ and partnership process with support from the Partnership for Maternal, Newborn, and Child Health (PMNCH), The BMJ, and a global steering committee.

The resulting 12 country case studies ${ }^{4}$ of multisectoral collaboration, selected from over 300 initial proposals, provide rich insights and collectively inform a synthesis paper of key lessons and an emergent collaborative model. ${ }^{6}$ The series provides advocacy and evidence for the power of a "learning society"-a phrase originally coined by educational philosopher Robert Hutchins $^{7}$-that has continuous learning, active citizenship, and social wellbeing as its primary goals.

Four specific lessons stand out from the country case studies. Firstly, as with the universality of the SDGs, multisectoral collaboration has relevance across diverse geographical, economic, social, cultural, and historical contexts, and-crucially-the modalities employed are remarkably similar across settings. In other words, there is a knowledge base to share on "what works" in multisectoral collaboration.

Secondly, the case studies show the dynamic and evolving nature of multisectoral collaboration. Stakeholders and their engagement change across different components and periods, highlighting the importance of realistic time frames, diverse evidence and ideas, and of "learning and adapting while doing" to yield transformative results.

Thirdly, multisectoral collaboration is a managed process in response to a challenge or opportunity, aimed at disrupting "business as usual" arrangements and replacing these with intentional, innovative actions framed in a way that multiple sectors can contribute.

Finally, these "real world" examples of multisectoral collaboration, many taken to national scale, allow governments and development partners to learn from each other and so target investments to catalyse transformative change.

But let's be clear, the learning environment in which knowledge was developed and shared across sectors, as described in the 12 country case studies, is not easy to create or sustain. The case studies arose from an open call for submissions by PMNCH for "success stories" of multisectoral collaboration across the six thematic priorities of the Every Woman Every Child initiative. Success is a fuzzy concept, open to debate and multiple interpretations and metrics. ${ }^{8}$ The invitation to learn only from success, however, sets up some interesting tensions.

One particular tension-which strikes at the heart of the use of case studies as a source of knowledge and as a basis for accountable reporting of progress-is the challenge of asking leaders to judge and report on the success of their own initiatives. The case studies in this series were subject to rigorous peer review and guided by specific questions in the methods guide ${ }^{5}$ to encourage self reflection and critique. Important insights come from authors explicitly describing uncertainty and areas of challenge.

In the drive for "progress," particularly around emotive subjects such as the health and wellbeing of women and children, there is often pressure to suppress key lessons on what has not worked. This effect is evident in publication bias against negative trials, for example, and in the hard-to-reach internal project reports of funders or implementers. But all failures are opportunities to learn: "Ever tried. Ever failed. No matter. Try again. Fail again. Fail better." " A genuine learning society must allow room for open and confident sharing of lessons from failure. This environment needs nurturing at all levels, including sufficient incentivespolitical, financial, and societal.

We're launching the series at the Partners' Forum in New Delhi in December 2018, where the country case studies will provide a refreshing glimpse of the benefits of reflection and openness. But there's much more to do. We call upon the diverse communities in the readership of The BMJ and those attending the forum to push for more effective and open communication, not just on successes but also on the "heroic failures" ${ }^{9}$ in health and developmentnamely, those other opportunities from which we must learn.

Competing interests: We have read and understood the BMJ Group policy on declaration of interests and have no interests to declare.

Provenance and peer review: Commissioned; not externally peer reviewed.

Wendy J Graham, professor1

Shyama Kuruvilla, senior strategic adviser ${ }^{2}$

Rachael Hinton, technical officer ${ }^{3}$ 
Emma Veitch, associate editor ${ }^{4}$

Paul J Simpson, international audience editor ${ }^{4}$

${ }^{1}$ London School of Hygiene and Tropical Medicine, London, UK

${ }^{2}$ World Health Organization, Geneva, Switzerland

${ }^{3}$ Partnership for Maternal, Newborn, and Child Health, Geneva, Switzerland

${ }^{4}$ The BMJ, London, UK

Correspondence to: W Graham

wendy.graham@lshtm.ac.uk

\section{A) Check for updates}

1 Sriskandarajah D. Warm and cuddly global goals? The international community must get real. Guardian
2017 Dec 5. www.theguardian.com/working-indevelopment/2017/dec/05/warm-and-cuddlyglobal-goals-sdgs-international-community-has-toget-real.

2 Partnership for Maternal, Newborn, and Child Health. Success factors for women's and children's health study series: journal articles and country reports. 2015. www.who.int/pmnch/ successfactors/en.

3 Lozano R, Fullman N, Abate D, et al. Measuring progress from 1990 to 2017 and projecting attainment to 2030 of the health-related Sustainable Development Goals for 195 countries and territories: a systematic analysis for the Global Burden of Disease Study 2017. Lancet 2018;392:2091-138. doi:10.1016/S0140-6736(18)32281-5

4 Making multisectoral collaboration work. www.bmj. com/multisectoral-collaboration
5 Partnership for Maternal, Newborn, and Child Health. Methods guide for country case studies on successful collaboration across sectors for health and sustainable development. World Health Organization, 2018. www.who.int/pmnch/knowledge/case-studymethods-guide.pdf.

6 Kuruvilla S, Hinton R, Boerma T, et al. Business not as usual: how multi-sectoral collaboration can promote transformative change for health and sustainable development. BMJ 2018;363:k4771.

7 Hutchin R. The learning society. University of Chicago Press, 1968.

8 Pawson $\mathrm{R}$. The science of evaluation: a realist manifesto. Sage, 2013

9 Beckett S. Worstward Ho. 1983. https://genius.com/ Samuel-beckett-worstward-ho-annotated.

Cite this as: BMJ 2018;363:k4868

http://dx.doi.org/10.1136/bmj.k4868 